\title{
Protective Effects of Mangifera indica L. Extract Against Lipofundin- induced Oxidative Stress in Rats
}

\author{
Livan Delgado Roche* and Ángela Fraga Pérez
}

Center of Studies for Research and Biological Evaluations, Pharmacy and Food Sciences College, University of Havana, Cuba

\begin{abstract}
Lipofundin is a lipid rich emulsion used in parenteral nutrition. It is known that Lipofundin induces an oxidative stress state characterized by an increase of lipid peroxidation and a dramatic depletion of antioxidants. The aim of the present study was to evaluate the effects of an aqueous extract of Mangifera indica L., on Lipofundin-induced oxidative stress. Male Sprague Dawley rats were treated orally with $200 \mathrm{mg} / \mathrm{kg}$ of Vimang ${ }^{\circledR}$, followed by an intravenous dose of 2 $\mathrm{mL} / \mathrm{kg}$ Lipofundin, daily, for 8 days. Selected oxidative stress biomarkers were then measured spectrophotometrically. The results showed that Vimang ${ }^{\circledR}$ produced significant $(\mathrm{p}<0.05)$ reduction of malondialdehyde, total hydroperoxides and advanced oxidation protein products, while the activities of superoxide dismutase and catalase were positively modulated. A significant $(\mathrm{p}<0.05)$ reduction of peroxidation potential and a preservation of glutathione and total antioxidant status was also observed. Our data demonstrated that Vimang ${ }^{\circledR}$ protects against Lipofundin-induced oxidative stress, which is an important finding that further reinforces the antioxidant properties of this natural product.
\end{abstract}

Keywords: Magnifera indica aqueous extract, oxidative stress, lipid peroxidation, lipofundin

\section{INTRODUCTION}

Artificial fat emulsions are widely used in parenteral nutrition [1]. Lipofundin is one such fat emulsion used as a source of calories for patients requiring parenteral nutrition. Jellinek et al. showed that this emulsion induced atherosclerotic lesions in rabbits [2], and recently our group has demonstrated that Lipofundin promotes high susceptibility to lipid peroxidation (LPO) in rabbits after 8 days of treatment [3]. These observations present a serious disadvantage to the use of Lipofundin in the clinical practice.

Under oxidative stress (OS) conditions, reactive oxygen species (ROS) have strong oxidizing ability which can induce damage to lipids, proteins and nucleic acids, with the consequent change in their structures and functions. On the other hand, antioxidant mechanisms are depleted in OS, and in many cases it is necessary to administer exogenous antioxidants [4].

Vimang ${ }^{\circledR}$ is an aqueous extract obtained from the stem bark of selected varieties of Mangifera indica L. (Anacardiaceae), which is a defined mixture of components (polyphenols, terpenoids, steroids, fatty acids and microelements). In Cuba, the aqueous extract of this plant is used to improve the quality of life in patients with elevated physical stress. In folk medicine the extract is recommended as antispasmodic, antipyretic and antiinflammatory. As a result, Vimang ${ }^{\circledR}$ was extensively tested both in vitro and in vivo studies to confirm these pharmacological properties. This has led to the use of

\footnotetext{
*Address correspondence to this author at Center of Studies for Research and Biological Evaluations, Pharmacy and Food Sciences College, University of Havana, Ave 23 No. 21425 e/ 214 y 222, La Coronela, La Lisa, La Habana, Cuba, CP 13 600; Tel: 271-9531/38; E-mails: ldelgado@ifal.uh.cu or ldelgadoroche@gmail.com
}

Vimang as supplement in the treatment of various pathologies such as gastric and dermatological disorders, AIDS, cancer and asthma [5]. Some of the main components of Vimang $^{\circledR}$ (mangiferin 20\%, amentoflavone $15 \%$, betasitosterol $2.5 \%$, daucosterol $1.7 \%$ ) have shown antioxidant properties in vitro and important pharmacological activities in vivo, including antiinflammatory and immunomodulatory effects [6-8]. The presence of selenium as an inorganic compound in Vimang ${ }^{\circledR}(0.05 \%)$ is also important in the antioxidant mechanism of this extract [5]. Vimang ${ }^{\circledR}$ has been evaluated for acute and subchronic toxicity, genotoxicity and irritability and was found to be non-toxic [9].

The effects of Vimang ${ }^{\circledR}$ on Lipofundin-induced OS had not been studied previously. Taking into account the previous reports, the aim of the present work was to evaluate the effects of $M$. indica bark extract on serum and hepatic redox biomarkers in rats treated with Lipofundin.

\section{MATERIALS AND METHODS}

\section{Materials}

All the reagents were purchased from Sigma-Aldrich (USA)

\section{Preparation of Mangifera indica Extract}

The stem bark of M. indica was collected from 10 plants grown in a fruit farm from Artemisa, without affecting the ecosystem. Bark was collected free of microbial contamination. The voucher specimen was deposited at LABIOFAM Herbarium (Havana, Cuba) under the code QF808. The samples were subsequently dried and milled to obtain particles of around $5 \mathrm{~cm}$. The industrial extract obtained by decoction with etanol/water $(1: 1 ; \mathrm{v} / \mathrm{v})$ at room temperature was drying. 
A homogeneous brown powder with a particle size of 30-60 $\mu \mathrm{M}$ was obtained and dissolved in distilled water for pharmacological studies. The end product (Vimang ${ }^{\circledR}$ ) was kindly provided by LABIOFAM, Havana, Cuba.

\section{Preparation of Solutions}

Vitamin $\mathrm{C}$ and Vimang ${ }^{\circledR}$ were dissolved in distilled water, while vitamin E was dissolved in sunflower oil.

\section{Lipofundin Composition}

Lipofundin MCT/LCT 20\% (Braun Melsungen AG, Melsungen, Germany) is a lipid emulsion containing soya oil $100 \mathrm{~g}$, medium-chain triglycerides $100 \mathrm{~g}$, glycerol $25 \mathrm{~g}$, egg lecithin $12 \mathrm{~g}$, $\alpha$-tocopherol $170 \pm 40 \mathrm{mg}$, and sodium oleate/water for injection in sufficient quantity to $1,000 \mathrm{~mL}$.

\section{Animals and Experimental Design}

Male Sprague Dawley rats (200-250 g) were obtained from CENPALAB (Mayabeque, Cuba). The animals were housed in a controlled environment at $23 \pm 2{ }^{\circ} \mathrm{C}$ and acclimatized 7 days before experiments ( $12 \mathrm{~h}$ light-dark cycles). The present protocol was approved by the Institutional Animal Ethical Committee and all procedures were in accordance with its guidelines. All animals were allowed to have free access to food (standard diet for rodents, CENPALAB) and water. $M$. Indica extract $(200 \mathrm{mg} / \mathrm{kg})$ was orally administered to the first group; while ascorbic acid (vitamin C) plus $\alpha$-tocopherol (vitamin E), $100 \mathrm{mg} / \mathrm{kg}$ respectively, were orally administered to the second one. The procedure was repeated daily for 7 days. Lipofundin $(2 \mathrm{~mL} / \mathrm{kg})$ was then intravenously administered for 8 consecutive days [10]. The third group received a daily dose of normal saline for 7 days before the administration of the same dose $(2 \mathrm{~mL} / \mathrm{kg})$ of Lipofundin. The fourth group did not receive any treatment. Following completion of the protocol the animals were anesthetized with ketamine hydrochloride ( $5 \mathrm{mg} / \mathrm{kg}$ i.m.), and euthanized with an overdose of sodium pentobarbital (90 $\mathrm{mg} / \mathrm{kg}$, i.v.)

Blood samples were taken from abdominal aorta, while hepatic tissue was quickly removed. Blood was immediately centrifuged at $2,500 \mathrm{~g}$, at $4{ }^{\circ} \mathrm{C}$ for $10 \mathrm{~min}$, then, serum was collected and aliquots were stored at $-70^{\circ} \mathrm{C}$ until analysis.

The liver was homogenized in $20 \mathrm{mM} \mathrm{KCl} /$ histidine buffer, $\mathrm{pH} 7.4,1: 10 \mathrm{w} / \mathrm{v}$ using a tissue homogenizer at $4{ }^{\circ} \mathrm{C}$ then centrifuged for $10 \mathrm{~min}$ at $12,000 \mathrm{~g}$. The supernatants were taken and stored at $-70{ }^{\circ} \mathrm{C}$ for analysis.

\section{Total Protein Content in Homogenates}

Total proteins levels were determined as described previously by Bradford using bovine serum albumin standard [11].

\section{Lipid Peroxidation Biomarkers}

Malondialdehyde (MDA) levels were measured at 586 $\mathrm{nm}$ using the LPO-586 kit Total hydroperoxides (TH) was measured at $560 \mathrm{~nm}$ by Bioxytech $\mathrm{H}_{2} \mathrm{O}_{2}-560$ kit.

\section{Susceptibility to Lipid Peroxidation Assay}

In order to determine susceptibility to lipid peroxidation, serum samples were incubated with a solution of $2 \mathrm{mM}$ copper sulphate at $37{ }^{\circ} \mathrm{C}$ for $24 \mathrm{~h}$. Peroxidation potential was calculated sustracting the relative content of MDA at $24 \mathrm{~h}$ to the one calculated without copper-induced lipid peroxidation [12].

\section{Oxidative Damage to Proteins}

The advanced oxidation protein products (AOPP) were measured as described by Witko-Sarsat et al. [13]. Briefly, the technique consists in treating $100 \mu \mathrm{L}$ of serum in phosphate buffer saline solution $(1 \mathrm{~mL})$ with $50 \mu \mathrm{L}$ of potassium iodide $1.16 \mathrm{M}$ followed by $100 \mu \mathrm{L}$ of acetic acid. The absorbance of the reaction mixture was immediately read at 340 $\mathrm{nm}$. AOPP concentration was expressed as $\mu \mathrm{M}$ of chloramines- $\mathrm{T}$. The standard, chloramine $\mathrm{T}$, was used at intervals of $5-100 \mu \mathrm{M})$.

\section{Enzymatic Antioxidant Defenses}

Superoxide dismutase (SOD) activity was evaluated by using a commercial kit where xanthine and xanthine oxidase were used to generate superoxide anion radicals $\left(\mathrm{O}_{2}{ }^{-{ }^{-}}\right)$, which react with 2-(4-iodophenyl)-3-(4-nitrophenol)-5phenyltetrazolium chloride (INT) to form a red formazan dye. SOD activity was measured by the inhibition degree of this reaction. Catalase (CAT) activity was determined by following the decomposition of hydrogen peroxide $\left(\mathrm{H}_{2} \mathrm{O}_{2}\right)$ at $240 \mathrm{~nm}$ at $10 \mathrm{~s}$ intervals during $1 \mathrm{~min}$ [14].

\section{Non Enzymatic Antioxidant Defenses}

After precipitation of thiol proteins adding acetonitrile to the samples, the reduced glutathione (GSH) levels were measured according to the method of Sedlak and Lindsay [15] with Ellman's reagent (5,5 dithiobis-2-nitrobenzoic acid), the absorbance was measured at $412 \mathrm{~nm}$. Purified GSH was used to generate standard curve.

\section{Total Antioxidant Status}

The total antioxidant status was determined using a Randox TAS kit Cat No. 2332. In the assay ABTS (2,2-Azinodi-[3-ethylbenzthiazoline sulphonate]) is incubated with a peroxidase (metmyoglobin) and hydrogen peroxide $\left(\mathrm{H}_{2} \mathrm{O}_{2}\right)$ to produce the radical cation $\mathrm{ABTS}^{\circ+}$. This has a relatively stable blue-green color, which is measured at $600 \mathrm{~nm}$.

\section{RESULTS}

The effect of mango extract supplementation on lipofundin-induced LPO biomarkers are shown in Table 1. Preventive treatment with the natural product minimized the damages in serum and liver, induced by lipofundin administration. Mango extract maintained the serum peroxidation potential and $\mathrm{TH}$ concentration at level of controls, while inducing significant $(\mathrm{p}<0.05)$ reduction of systemic MDA and AOPP levels. In all cases, Vimang ${ }^{\circledR}$ induced a major protection (statisticaly significant $\mathrm{p}<0.05$ ) by comparison with the animals treated with vitamins. In hepatic tissue there was significant reduction of biomolecules damages $(p<0.05)$, highlighting the effects of Vimang ${ }^{\circledR}$ on MDA levels, which were maintained at level of controls. The rest of biomarkers were significantly lower than in Lipofundin and vitamins treated groups.

The effect of Vimang ${ }^{\circledR}$ on selected antioxidant enzymes and markers are shown in Table 2 . The enzymatic activities 
Table 1. Effects of Vimang ${ }^{\circledR}$ on Lipofundin-Induced Biomolecules Damage Biomarkers

\begin{tabular}{|c|c|c|c|c|}
\hline Serum Biomarkers & $\begin{array}{c}\text { Control } \\
(n=5)\end{array}$ & $\begin{array}{l}\text { Lipofundin } \\
\qquad(\mathbf{n}=5)\end{array}$ & $\begin{array}{c}\text { Vimang }{ }^{\circledR}+\text { Lipofundin } \\
((n=5)\end{array}$ & $\begin{array}{c}(\text { Vit C + Vit E) }+ \text { Lipo- } \\
\text { fundin } \\
(n=5)\end{array}$ \\
\hline $\mathrm{TH}, \mu \mathrm{M}$ & $30.88 \pm 2.31$ & $56.24 \pm 3.17^{*}$ & $34.60 \pm 5.86$ & $45.24 \pm 5.18^{\dagger}$ \\
\hline $\mathrm{PP}, \mu \mathrm{M}$ of MDA & $9.98 \pm 1.16$ & $18.01 \pm 0.98^{*}$ & $10.48 \pm 0.76$ & $13.01 \pm 0.33^{\dagger}$ \\
\hline \multicolumn{5}{|l|}{ Liver Biomarkers } \\
\hline $\mathrm{MDA}, \mu \mathrm{M} / \mathrm{mgPr}$ & $2.91 \pm 0.70$ & $6.59 \pm 0.80 *$ & $2.84 \pm 0.91$ & $3.06 \pm 0.26$ \\
\hline $\mathrm{TH}, \mu \mathrm{M} / \mathrm{mgPr}$ & $19.30 \pm 1.66$ & $33.71 \pm 2.89^{*}$ & $22.09 \pm 2.01^{\dagger}$ & $26.76 \pm 1.70^{*}$ \\
\hline
\end{tabular}

Notes: The values are the means \pm standard deviation. Different symbols represent statistical differences ( $<<0.05)$. MDA: malondialdehyde, TH: total hydroperoxides, PP: peroxidation potential, AOPP: advanced oxidation protein products. The concentration of liver biomarkers is expressed per milligrams of total proteins (Pr).

of SOD and CAT were significantly $(p<0.05)$ higher in the Lipofundin group by comparison to the control groups, whereas the extract-treated group showed activities closer to the untreated group (negative control). A significant $(\mathrm{p}<0.05)$ improvement in SOD activity was observed in animals treated with mango extract. The serum CAT activity of this group was maintained at the level of the control animals and was significantly $(p<0.05)$ lower than in group treated with vitamins.

On the other hand, Table 2 shows that the extract restored the serum and hepatic levels of GSH and total antioxidant status. There was a significant reduction $(p<0.05)$ of nonenzymatic antioxidants in Lipofundin treated animals compared with the rest. It is important to highlight that mango bark extract treatment incremented the bioavailability of these important antioxidant systems.

\section{DISCUSSION}

The use of Lipofundin for hyperlipidemia and atherosclerotic lesions induction has been reported by Jellinek et al. [2] and by Noa et al. $[10,16]$. Recently, our group showed that Lipofundin induces LPO and a depletion of antioxidant substances in rabbits $[3,17]$. LPO induces disturbance of cell structures, alteration of integrity, fluidity, and permeability, and functional loss of biomembranes, modifies low density lipoproteins (LDL) to proatherogenic and proinflammatory forms, and generates potentially toxic products such as MDA and lipoperoxides [18]. The MDA levels were positively modified by Vimang, as well as vitamins treatment. This is an important fact, because high serum levels of MDA represent a predictor of atherosclerosis and other pathological diseases [3]. Martínez et al. demonstrated that this natural product inhibited the formation of MDA in brain and hepatic ischemic damage $[18,19]$. In this paper the authors suggest that the main mechanism responsible of LPO inhibition may be associated with ${ }^{\circ} \mathrm{OH}$ radical scavenging properties of the mango extract [20], since ${ }^{\circ} \mathrm{OH}$ radicals are considered major promoter of LPO in vitro and in vivo [21].
Lipid hydroperoxides are intermediary products from LPO [21]. Lipid hydroperoxides in the presence or absence of catalytic metal ions also give rise to a large variety of products, including short chain aldehydes, which can be used to assess the degree of LPO in a system [22]. Many natural products are able to inhibit the lipoperoxides formation [18]; indeed we demonstrated that extract inhibited the in vivo formation of TH, and we thought that aqueous extract is able to abrogate the formation of this reactive molecules mainly through its capacity to scavenge ${ }^{\circ} \mathrm{OH}$ and other ROS.

Proteins represent another target for ROS under chronic OS condition [23]. The AOPP, as a surrogate marker of myeloperoxidase-induced protein oxidation, has been associated with chronic inflammation and related diseases [24]. The anti-inflammatory properties of have been demonstrated by Garrido et al. [25, 26]. We suggest that this may be responsible for the low levels of AOPP observed in the treated animals.

The extract of mango contains a defined mixture of components such as polyphenols, terpenoids, steroids, fatty acids and microelements. The major components such as mangiferin, amentoflavone, friedelin, daucosterol and betasitosterol have already been identified [9]. These substances exert very potent scavenger activity on ${ }^{\circ} \mathrm{OH}$ radicals and hypochlorous acid, and have antioxidants properties both in vitro and in vivo studies [6]. Taking into account our findings, we suggest that mango extract may inhibit LPO and protein oxidation through a mechanism of break chain.

On the other hand, mangiferin, the main component of mango extract, possesses potent antioxidant properties. We suggest that mangiferin may contribute to diminish Lipofundin-induced damage. Jagieta and Venkatesha demonstrated that mangiferin scavenges ROS and protects against ultraviolet irradiation-induced OS [27]. Also, Nair and Devi showed that mangiferin has hypolipidemic properties [28]. Although we did not determined the effects of mango extract on serum lipid profiles, even though we have previously shown that Lipofundin induces hyperlipidemia and subse- 
Table 2. Effects of Vimang ${ }^{\circledR}$ Supplementation on Antioxidant Defenses

\begin{tabular}{|c|c|c|c|c|}
\hline Serum Biomarkers & $\begin{array}{c}\text { Control } \\
(\mathbf{n}=5)\end{array}$ & $\begin{array}{l}\text { Lipofundin } \\
\qquad(\mathrm{n}=5)\end{array}$ & $\begin{array}{c}\text { Vimang }{ }^{\circledR}+\text { Lipofundin } \\
((n=5)\end{array}$ & $\begin{array}{c}(\text { Vit } \mathbf{C}+\underset{\text { Vit E })}{\text { fundin }}+\text { Lipo- } \\
(\mathrm{n}=\mathbf{5})\end{array}$ \\
\hline $\mathrm{CAT}, \mathrm{U} / \mathrm{L} / \mathrm{min}$ & $1126.34 \pm 22.31$ & $2056.24 \pm 19.57^{*}$ & $1134.60 \pm 25.33$ & $1445.77 \pm 36.21^{\dagger}$ \\
\hline $\mathrm{GSH}, \mu \mathrm{M}$ & $349.42 \pm 9.98$ & $209.11 \pm 11.65^{*}$ & $288.49 \pm 10.76^{\dagger}$ & $279.09 \pm 11.73^{\dagger}$ \\
\hline \multicolumn{5}{|l|}{ Liver Biomarkers } \\
\hline $\mathrm{SOD}, \mathrm{U} / \mathrm{mL} / \mathrm{min} / \mathrm{mgPr}$ & $42.73 \pm 4.88$ & $79.68 \pm 10.21 *$ & $54.34 \pm 2.98^{\dagger}$ & $59.79 \pm 9.71^{\dagger}$ \\
\hline $\mathrm{CAT}, \mathrm{U} / \mathrm{L} / \mathrm{min} / \mathrm{mgPr}$ & $4218.70 \pm 21.96$ & $6121.91 \pm 32.25^{*}$ & $5022.27 \pm 21.08^{\dagger}$ & $5128.92 \pm 31.00^{\ddagger}$ \\
\hline $\mathrm{GSH}, \mu \mathrm{M} / \mathrm{mgPr}$ & $613.55 \pm 12.92$ & $426.34 \pm 11.72 *$ & $529.39 \pm 13.74^{\dagger}$ & $481.81 \pm 11.52^{\dagger}$ \\
\hline
\end{tabular}

Notes: The values are the means \pm standard deviation. Different symbols represent statistical differences $(p<0.05)$. The concentration of liver biomarkers is expressed per milligrams of total proteins (Pr). SOD: superoxide dismutase, CAT: catalase, GSH: glutathione, TAS: total antioxidant status.

quently OS [17]. It is possible that the extract, through its hypolipidemic properties, reduces the level of hyperlipidemia-induced ROS production in these animals.

SOD and CAT play an important role in the antioxidant defense system [29]. Superoxide $\left(\mathrm{O}_{2}{ }^{-}\right)$by itself is unable to cause cell death, due to its short half-life and poor reactivity in aqueous solution [30], while $\mathrm{H}_{2} \mathrm{O}_{2}$, produced indirectly by dismutation of $\mathrm{O}_{2}{ }^{-}$, appears to be cytotoxic to cells, since exogenous CAT completely prevents cell damage [31]. The positive modulation by mango aqueous extract of both antioxidant enzymes suggests that ROS generation in the treated animals is inhibited by this natural product.

The non-enzymatic antioxidant defenses also play an important role in protection against OS. The most abundant antioxidant in cells is GSH, a tripeptide that may interact with ROS and offer protection to the organism [32]. On the other hand TAS is a useful tool to determine the bioavailability of non-enzymatic antioxidants. The preservation of both GSH and by mango extract treatment is an important finding, since GSH is considered one of the main xenobiotic detoxification pathways [33], while total antioxidant responds to an appropriate antioxidant status. It is important to highlight that our results are in accordance with previous reports [16].

Finally, the peroxidation potential shows the susceptibility to copper-induced LPO as a balance between pro-oxidant factors and antioxidant protection in the homogenates. The results indicate that this balance was better in groups treated with mango extract which is likely due to the free radicals scavenger properties of the extract [6].

\section{CONCLUSIONS}

Our data demonstrated that $M$. indica bark extract protects against the Lipofundin-induced OS in rats. This confirms earlier reports on the antioxidant properties of this extract.

\section{ABBREVIATIONS}

$\mathrm{AOPP}=\quad$ Advanced oxidation protein products
CAT $=$ Catalase
$\mathrm{GSH}=$ reduced glutathione
$\mathrm{H}_{2} \mathrm{O}_{2}=$ Hydrogen peroxide
$\mathrm{LDL}=$ Low density lipoprotein
LPO $=$ Lipid peroxidation
MDA $=$ Malondialdehyde
$\mathrm{O}_{2}{ }^{--}=$Superoxide anion
OS $=$ Oxidative stress
ROS $=$ Reactive oxygen species
SOD $=$ Superoxide dismutase
$\mathrm{TH}=\quad$ Total hydroperoxides

\section{CONFLICT OF INTEREST}

None declared.

\section{ACKNOWLSGEMENTS}

Authors gratefully acknowledge the technical assistance of the staff of Biochemistry Laboratory from Center of Studies for Research and Biological Evaluations, University of Havana.

\section{REFERENCES}

[1] Calder, P.C.; Jensen, G.L.; Koletzko, B.V.; Singer, P.; Wanten, G.J.A. Lipid emulsions in parenteral nutrition of intensive care patients: current thinking and future directions. Intens. Care Med., 2010, 36, 735-749.

[2] Jellinek, H.; Harsing, J.; Fuzcesi, S. A new model for arteriosclerosis. An electron microscopy study of the lesions induced by i.v. administered fat. Atherosclerosis, 1982, 43, 7-18.

[3] Delgado, L.; Acosta, E.; Hernández-Matos, Y.; Bécquer, M.A.; Vázquez A.M.; Fernández, E. High levels of lipid peroxidation induced by Lipofundin administration correlates with atherosclerotic lesions in rabbits. Pharmacologyonline, 2010, 3, 727-736.

[4] Aruoma, O.I. Methodological considerations for characterizing potential antioxidant actions of bioactive components in plant foods. Mutat. Res., 2003, 523, 9-29. 
[5] Núñez-Sellés, A.; Vélez-Castro, H.; Agüero-Agüero, J.; GonzálezGonzález, J.; Naddeo, F.; De Simone, F. Isolation and quantitative analysis of phenolic antioxidants, free sugars, fatty acids and polyols from mango (Mangifera indica L.) stem bark aqueous decoction used in Cuba as nutritional supplement. J. Agric. Food Chem. 2002, 50, 762-6.

[6] Martínez-Sánchez, G.; Re, L.; Giuliani, A.; Núñez-Sellés, A.J.; Davison, G.P.; León, O.S. Protective effects of Mangifera indica L. extract, mangiferin and selected antioxidants against TPA-induced biomolecules oxidation and peritoneal macrophage activation in mice. Pharmacol. Res., 2000, 42, 565-573.

[7] Martínez-Sánchez, G.; Giuliani, A.; León, O.S.; Pérez, G.; NúñezSellés, A.J. Effect of Mangifera indica L. extract (QF808) on protein and hepatic microsome peroxidation. Phytother. Res., 2001, 15, 581-585.

[8] Martínez-Sánchez, G.; Rodríguez, M.A.; Giuliani, A.; NúñezSellés, A.J.; Pons, N.; León, O.S.; Re, L. Protective effect of Mangifera indica L. extract (Vimang®) on the injury associated with hepatic ischaemia reperfusion. Phytother. Res., 2003, 17, 197201.

[9] Centre of Pharmaceutical Chemistry, 1998. Pharmaceutical compositions including a mixture of polyphenols, terpenoids, steroids, fatty acids and microelements with antioxidant, analgesic, antiinflammatory and anti-spasmodic properties. Patent pending 203/98, OCPI. Havana, Cuba.

[10] Noa, M.; Mas, R.; de la Rosa, M.C.; Magranjer, J. Effect of policosanol on lipofundin-induced atherosclerotic lesions in rats. $J$. Pharm. Pharmacol., 1995, 47, 289-291.

[11] Bradford, M.M. A rapid and sensitive method for the quantitation of microgram quantities of protein utilizing the principle of proteindye binding. Anal. Biochem., 1976, 72, 248-254.

[12] Ozdemirler, G.; Mehmetcik, G.; Oztezcan, S.; Toker, G.; Sivas, A.; Uysal, M. Peroxidation potential and antioxidant activity of serum in patients with diabetes mellitus and myocardial infarction. Horm. Metab. Res., 1995, 27, 194-6.

[13] Witko-Sarsat, V.; Friedlander, M.; Nguyen-Khoa, T.; CapeillereBlandin, C.; Nguyen, A.T.; Canteloup, S.; Dayer, J.M.; Jungers, P.; Drueke, T.; Descamps-Latscha, B. Advanced oxidation protein products as novel mediators of inflammation and monocyte activation in chronic renal failure. J. Immunol., 1998, 161, 2524-2532.

[14] Boehringer Mannheim. Biochemica Information. A revised biochemical reference source. Enzymes for routine. $1^{\text {st }}$ ed., Berlin, Germany: Boehringer Mannheim, 1987, pp.15-16.

[15] Sedlak, J.; Lindsay, R.H. Estimation of total, protein-bound, and non-protein sulfhydril groups in tissue with Ellman's reagent. Anal. Biochem., 1968, 25, 192-205.

[16] Noa, M.; Más, R. Ateromixol y lesión ateroesclerótica en Conejos inducida por Lipofundin. Prog. Cien. Med., 1992, 6, 14-19.

[17] Delgado, L.; Acosta, E.; Fraga, A.; Bécquer, M.A.; Soto, Y.; Falcón, V.; Vázquez, A.M.; Martínez, G.; Fernández, E. Lipofundininduced hyperlipidemia promotes oxidative stress and atherosclerotic lesions in New Zealand White rabbits. Int. J. Vasc. Med., 2011, 2012, 1-7.
[18] Tani, S.; Nagao, K.; Anazawa, T.; Kawamata, H.; Furuya, S.; Fuji, T. Association of plasma level of malondialdehyde-modified lowdensity lipoprotein with coronary spastic angina: implication of acute coronary events. Int. J. Cardiol., 2009, 135, 202-206.

[19] Martínez-Sánchez, G.; Candelario-Jalil, E.; Giuliani, A.; León, O.S.; Sam, S.; Delgado, R.; Núñez-Sellés, A.J. Mangifera indica L. extract (Vimang) reduces ischaemia-induced neuronal loss and oxidative damage in the gerbil brain. Free Radic. Res., 2002, 46, 117.

[20] Martínez-Sánchez, G.; Candelario-Jalil, E.; Giuliani, A.; León, O.S.; Sam, S.; Delgado, R.; Núñez-Sellés, A.J. Evaluation of the in vitro antioxidant activity of Mangifera indica L. Extract (Vimang). Phytother. Res., 2002, 14, 424-7.

[21] Niki, E. Lipid peroxidation: physiological levels and dual biological effects. Free Radic. Biol. Med., 2009, 47: 469-484.

[22] Abuja, P.M.; Albertini, R. Methods for monitoring oxidative stress, lipid peroxidation and oxidation resistance of lipoproteins. Clin. Chim. Acta, 2001, 306, 1-17.

[23] Martínez-Sánchez, G.; Giuliani, A.; Pérez-Davison, G.; León, O.S. Oxidized proteins and their contribution to redox homeostasis. Redox Rep., 2005, 10, 175-185.

[24] Capeillére-Blandin, C.; Gansson, V.; Descamps-Latscha, B.; Witko-Sarsat, V. Biochemical and spectrophotometric significance of advanced oxidized protein products. Biochim. Biophys. Acta, 2004, 1689, 91-102.

[25] Garrido, G.; González, D.; Delaporte, C.; Backhouse, N.; Quintero, G.; Núñez-Sellés, A.J.; Morales, J.A. Analgesic and antiinflammatory effects of Mangifera indica L. extract (Vimang). Phytother. Res., 2001, 15, 18-21.

[26] Garrido, G.; Delgado, R.; Lemus, Y.; Rodríguez, J.; García, D.; Núñez-Sellés, A.J. In vivo and in vitro anti-inflammatory activity of Mangifera indica L. extract (VIMANG ${ }^{\circledR}$ ). Pharmacol. Res., 2004, 50, 143-149.

[27] Nair, P.S.; Davi, C.S.S. Efficacy of mangiferin on serum and heart tissue lipids in rats subjected to isoprotenerol induced cardiotoxicity. Toxicology, 2006, 228, 135-139.

[28] Jagieta, G.C.; Venkatesha, V.A. Effect of Mangiferin on radiationinduced micronucleus formation in cultured human peripheral blood lymphocytes. Environ. Mol. Mutat., 2005, 46, 12-21.

[29] Halliwell, B.; Cross, C.E. Oxygen derived species: their relation to human diseases and environmental stress. Environ. Health. Perspect., 1994, 102, 5-12.

[30] Fridovich, I. Superoxide anion radical $\left(\mathrm{O}_{2}{ }^{-}\right)$, superoxide dismutase, and related matters. J. Biol. Chem., 1992, 272, 18515-18517.

[31] Day, B.J. Catalase and glutathione peroxidase mimics. Biochem. Pharmacol., 2009, 77, 285-296.

[32] Circu, M.L.; Tak, Y.A. Glutathione and apoptosis. Free Radic. Res., 2008, 42, 689-706.

[33] Filomeni, G.; Rotilio, G.; Ciriolo, M.R. Cell signaling and the glutathione redox system. Biochem. Pharmacol., 2002, 64, 1057 1064.

Received: December 13, 2011

Revised: February 28, 2012

Accepted: February 29, 2012

(C) Roche and Pérez; Licensee Bentham Open.

This is an open access article licensed under the terms of the Creative Commons Attribution Non-Commercial License (http:/creativecommons.org/ licenses/ by-nc/3.0/) which permits unrestricted, non-commercial use, distribution and reproduction in any medium, provided the work is properly cited. 